\title{
AOR
}

Selected Papers of \#AolR2020:

The 22nd Annual Conference of the Association of Internet Researchers Virtual Event / 13-16 Oct 2021

\section{LIZIQI AND CHINESE RURAL YOUTUBE VIDEOS: SCOPING A GENRE}

\author{
Crystal Abidin \\ Curtin University \\ Chen Guo \\ Zhengzhou University
}

\section{Introduction}

Chinese rural YouTube videos are videos produced by Chinese people and depicting people's daily activities in Chinese rural villages. This genre of videos generally contains rural village lifestyle and activities, including farming, cooking, crafting and some daily experiences. In order to create a nostalgic environment for audiences, some YouTubers use traditional decoration, or use soft instrumental music to emphasise a pastoral feeling. Audiences can see the imagery of the picturesque rural life and hear the local dialect when they watch these videos (Figures $1 \& 2$ ). With Chinese rural village videos and their followers proliferating exponentially on YouTube, these influencers have been empowered by digital technologies. Hence, it is important to scope the genre of Chinese rural YouTubers and analyze rural Chinese videos because the genre has aroused cultural, economic, and societal influence.

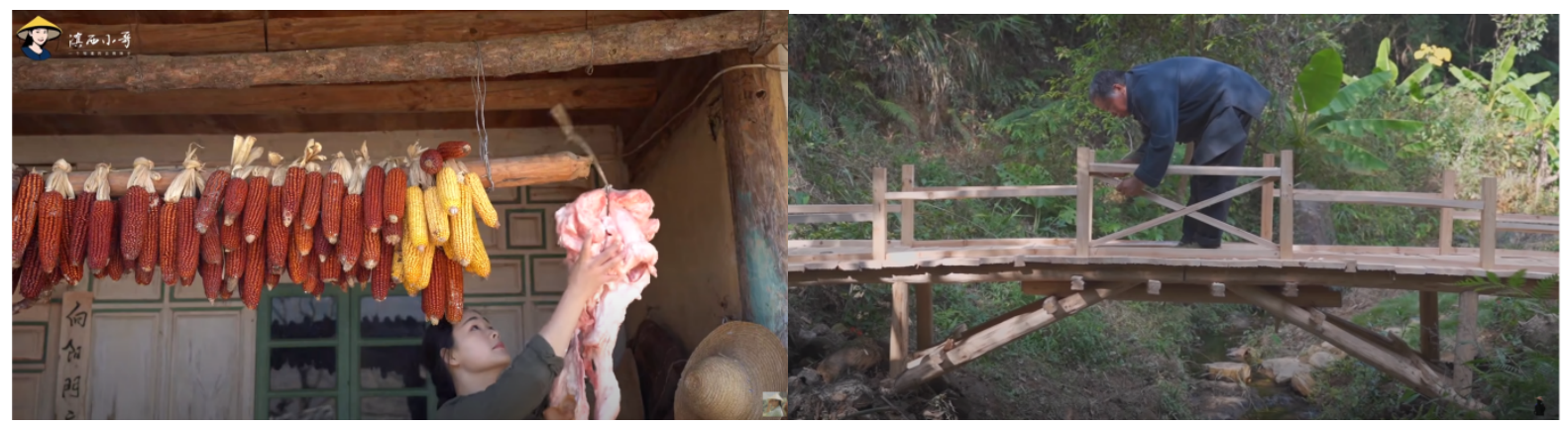

Figure 1 \& 2: Screenshot of examples of Chinese rural YouTube videos. (Source: Dianxi Xiaoge \& Grandpa Amu)

Suggested Citation (APA): Abidin, C. \& Guo, C. (2021, October). Liziqi and Chinese rural YouTube videos: Scoping a genre. Paper presented at AolR 2021: The 22nd Annual Conference of the Association of Internet Researchers. Philadelphia, PA, USA: AolR. Retrieved from http://spir.aoir.org. 
At present, the most popular and globally prolific Chinese rural influencer on YouTube is Liziqi (李子染), who has accumulated more than 14 million subscribers across her 124 videos uploaded since March, 2021 (Figure 3). Liziqi was selected as an ambassador for promoting the Chinese farmer harvest festival in 2020, chosen by the Communist Youth League as ambassador for promoting the economic empowerment of rural youth in 2019. It seems that the Chinese government has realised Liziqi's potential to promote Chinese rural culture and economy internationally and has sought various collaborations to leverage on the global scale of her internet celebrity. In response, scholars in China have focused on how rural influencers partake in collaboration and promotional work to stimulate awareness of rural products and local economies (i.e., Guo \& Cheng, 2020).

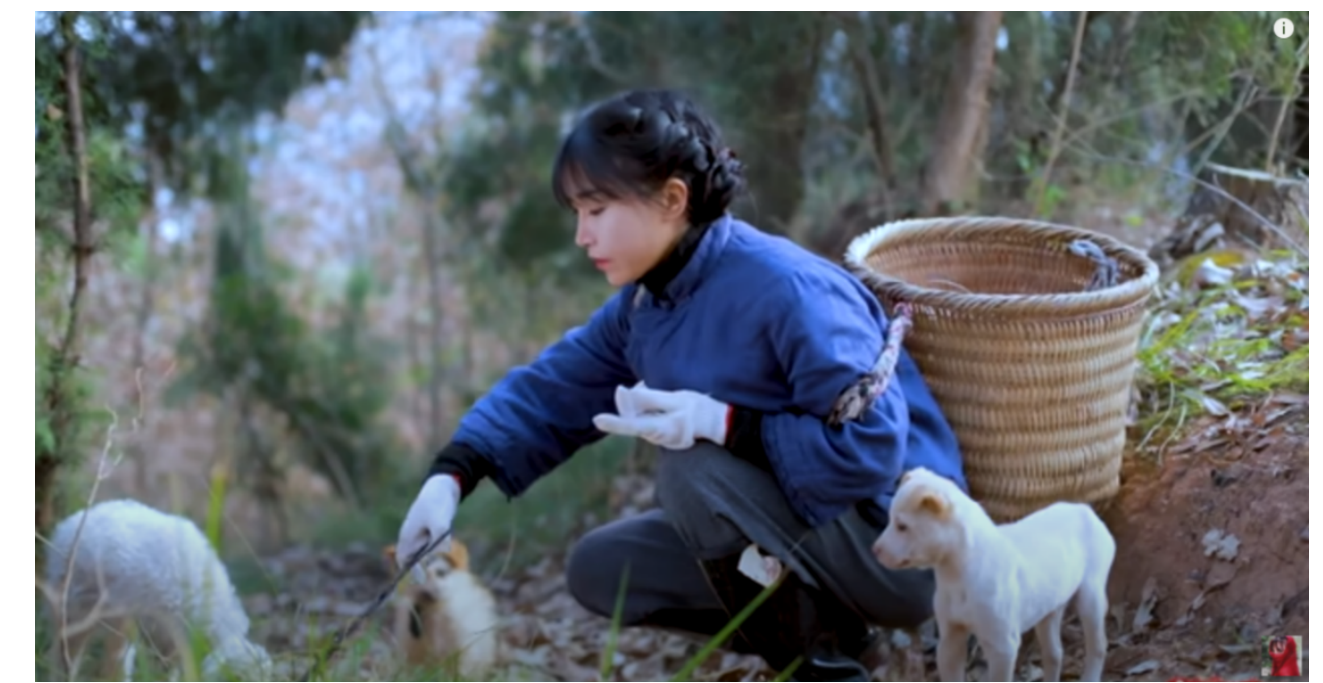

Figure 3: Screenshot of Liziqi's most popular video at the time of writing.

(Source: Liziqi)

Scholars have explored the role of digital technologies for rural influencers. Leong et al. (2016: 482) has researched how digital technology empowers the e-commerce ecosystem in marginalized communities and argued that rural communities can become 'drivers of change' when they are empowered by digital technologies. Zhang (2020) explored how the rural influencers in China, as the group on the edge of urbanization, frame themselves and perform 'rurality' to audiences. However, the research has not yet provided a scope or discussion of the genre of Chinese rural videos on YouTube.

This article aims to map out the emergent genre of Chinese rural influencers on YouTube, and consider how they empower themselves with internet technologies, and use the internet to gain independence on YouTube. While independence is frequently assumed to be about progressive politics, in the context of China, it can also reveal an attachment to individualization. Individualization refers to how the 'naturally autonomous' (Yan, 2010) operates in China, noting people's increased autonomy as a result of social and economic reforms. Under the digital environment, the development of digital technologies and the internet also play a role in promoting Chinese rural 
YouTubers' individualization. Individualization in China specifically means that people assume more responsibility and take proactive means to achieve a good life (Yan, 2010). Chinese rural YouTubers have used digital technology to gain emotional, intellectual and material independence, which helps them to get rid of the "trapped" situation.

\section{Methodology}

This study relied on YouTube's algorithmic recommendation of videos to understand how the platform 'categorizes' and 'promotes' related content to viewers. Using a brand new YouTube account on a clean slate, we started with Liziqi's channel as a 'starter dough' by watching the top 10 most viewed videos. At the end of each video, we noted all the recommended videos lined up, paying attention to new channels. Each time a new channel was recommended, we followed through to the account and watched the top 10 most viewed videos, and similarly noted the new channels recommended by the platform thereafter. We followed through this process for 5 rounds (Figure 4), and eventually manually amassed a corpus of 3480 video links from 205 channels in February 2021.

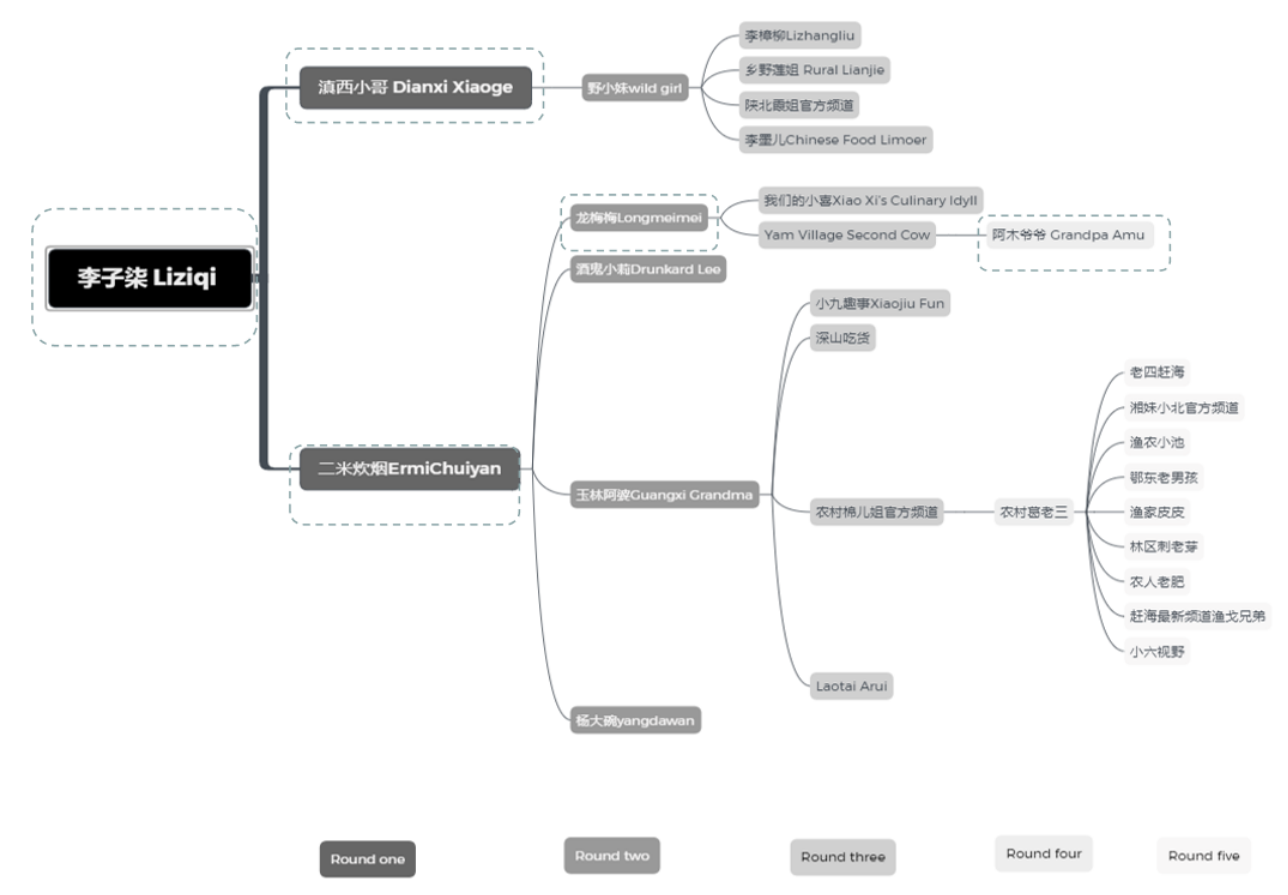

Figure 4: A sample of the 'Chinese rural YouTube' channels we had discovered through the iterative algorithmic recommendation from YouTube at the end of each video.

Based on specific selection criteria - such as channel visibility, geographical location, and audience engagement - we streamlined our corpus to 29 channels for closer examination. After a closer screening, in this abstract we presented our data from the the most viewed video from the top 5 channels (outlined in Figure 4). Guided by grounded theory (Glaser \& Strauss 2017), we closely surveyed various elements of 
each video, including the cover images, title, narrative structure, filming aesthetic, and so on. A truncated version of our codebook is below (Figure 5).

\begin{tabular}{|c|c|c|}
\hline CODE & CATEGORY & EXPLANATION \\
\hline \multirow[t]{2}{*}{$\begin{array}{l}\text { Location \& } \\
\text { Background }\end{array}$} & Indoor & $\begin{array}{l}\text { Videos were filmed indoors including in the kitchen, } \\
\text { rooms. }\end{array}$ \\
\hline & Outdoor & $\begin{array}{l}\text { Videos were filmed outdoors with natural surroundings, } \\
\text { including farmland, private yard or public places. }\end{array}$ \\
\hline \multirow[t]{4}{*}{$\begin{array}{l}\text { Thematic } \\
\text { content }\end{array}$} & $\begin{array}{l}\text { Activities relating } \\
\text { to agriculture }\end{array}$ & $\begin{array}{l}\text { Videos presenting people in the Chinese rural villages } \\
\text { doing gardening, planting, sowing, picking ingredients. }\end{array}$ \\
\hline & $\begin{array}{l}\text { Activities relating } \\
\text { to cooking/eating }\end{array}$ & $\begin{array}{l}\text { Videos presenting people in the Chinese rural villages } \\
\text { preparing food, different kinds of cooking, eating alone or } \\
\text { with family. }\end{array}$ \\
\hline & $\begin{array}{l}\text { Activities relating } \\
\text { to animals }\end{array}$ & $\begin{array}{l}\text { Videos presenting people in the Chinese rural villages } \\
\text { playing with pets, feeding husbandry animals, or catching } \\
\text { wild animals. }\end{array}$ \\
\hline & $\begin{array}{l}\text { Activities relating } \\
\text { to handcrafts }\end{array}$ & $\begin{array}{l}\text { Videos presenting people in the Chinese rural villages } \\
\text { making art craft or DIY. }\end{array}$ \\
\hline \multirow[t]{2}{*}{ People } & Alone & \multirow[t]{2}{*}{ People who emerged in videos. } \\
\hline & Together & \\
\hline \multirow[t]{6}{*}{ Paratext } & Subtitles & \multirow{2}{*}{$\begin{array}{l}\text { Chinese or English words are intended for Chinese or } \\
\text { international viewers to understand the conversation in } \\
\text { videos. }\end{array}$} \\
\hline & Closed caption & \\
\hline & Logo & $\begin{array}{l}\text { Words or pictures to advertise the Chinese rural } \\
\text { influencers or branding themselves. }\end{array}$ \\
\hline & $\begin{array}{l}\text { Description of } \\
\text { video content }\end{array}$ & $\begin{array}{l}\text { English or Chinese languages to explain the video content } \\
\text { and make it easier to understand, such as the name of } \\
\text { ingredients, the process of cooking a specific food. }\end{array}$ \\
\hline & Hashtag & Words to make videos easier for searching. \\
\hline & titles & $\begin{array}{l}\text { Words to introduce the video content and provide } \\
\text { eye-catching effect. }\end{array}$ \\
\hline \multirow[t]{2}{*}{ Sound } & Diegetic sound & $\begin{array}{l}\text { Diegetic sound refers to sound that happened together } \\
\text { when the videos were filmed, including chopping food, } \\
\text { conversation, eating, food boiling, and sound from } \\
\text { animals, such as bird singing, dag shouting. }\end{array}$ \\
\hline & $\begin{array}{l}\text { Non-diegetic } \\
\text { sound }\end{array}$ & $\begin{array}{l}\text { Non-diegetic sounds means sound that did not originate } \\
\text { from within the video's world. People in the video cannot } \\
\text { hear the non-diegetic sound. }\end{array}$ \\
\hline \multirow[t]{3}{*}{ Partnership } & Government & \multirow{3}{*}{$\begin{array}{l}\text { Collaboration with other partners to gain their influence or } \\
\text { for some specific purpose. }\end{array}$} \\
\hline & Other & \\
\hline & Brands & \\
\hline
\end{tabular}

Figure 5: Truncated summary of our codebook.

\section{Findings}

We present three preliminary findings in this abstract.

First, the genre of Chinese rural YouTube videos is constituted by some necessary elements in the video content, including rural scenery, thematic content of rural life activities, paratexts to introduce the content or (optionally) embed advertising, and the use of diegetic or non-diegetic sound to enhance the atmosphere. This genre shows 
people farming, feeding animals, gathering crops, and cooking in rural villages surrounded with natural scenery.

Second, by focusing on the cover image of videos, categories of videos, narrative structure, aesthetic styles, and thematic content of a video, we found these YouTubers engaged with themes of rurality, nostalgia, orientalism, exoticism, and commodification in the videos. This has a profound influence in culture, economy, and society because these videos have changed the stereotype of rural life and activities in China as being backward, and spread cultural knowledge globally.

Third, we found that Chinese rural YouTubers use digital technologies to empower themselves. Digital technologies have provide them a new way to achieve their individualization, by gain emotional (e.g. Dianxi Xiaoge expressed happiness when her videos are welcomed globally), intellectual (e.g. Rural people's autonomy from controlling imagery of lifestyle on traditional media), and material independence (e.g. Liziqi selling her own branding product).

This abstract presents a brief snippet of our larger study, which we hope can serve as a benchmark for future studies on Chinese rural YouTube videos.

\section{References}

Glaser, B. G., \& Strauss, A. L. (2017). Discovery of grounded theory: Strategies for qualitative research. Routledge.

Guo, N., \& Cheng, X. (2020). Research on the online sale model of agricultural products under the background of Internet celebrity economy (网红经济背景下农产品线上销售模 式研究). Price: Theory \& Practice, 04, 124-127. Retrieved from https://doi.org/10.19851/j.cnki.cn11-1010/f.2020.04.096

Leong, C. M. L., Pan, S.-L., Newell, S., \& Cui, L. (2016). The Emergence of SelfOrganizing E-Commerce Ecosystems in Remote Villages of China: A Tale of Digital Empowerment for Rural Development. MIS Q., 40(2), 475-484.

Yan, Y. (2010). The Chinese path to individualization. The British Journal of Sociology, 61(3), 489-512.

Zhang, X. (2020). The rural video influencers in China: on the new edge of urbanization. Retrieved from https://ecommons.cornell.edu/handle/1813/70319 